\title{
LA RELEVANCIA DE LA PLANIFICACIÓN EN EL PROCESO DE NEGOCIACIÓN: EL CASO DEL ACUERDO COMERCIAL PERÚ - ESTADOS UNIDOS
}

\author{
TERESA S. MERA
}

\author{
- Profesora de Estrategias de Negociación \\ Área Académica de Administración \\ Facultad de Negocios, UPC
}

De acuerdo con Flint (2001) la negociación es el "proceso de comunicación dinámico en el cual dos o más partes intentan resolver diferencias y defender intereses en forma directa para lograr una solución satisfactoria". Como tal, se trata de un proceso complejo en el cual se debe identificar el conflicto, así como los intereses de cada una de las partes y qué es lo que las motiva a participar en el proceso. Así, el proceso de negociación no debe dejarse librado a la casualidad o a la improvisación, sino que debe ser planificado antes del inicio del mismo a efectos de lograr la mejor solución posible para ambas partes de manera que el conflicto entre las mismas sea resuelto en base al consenso y de manera satisfactoria.

\section{LA PLANIFICACIÓN EN EL PROCESO DE NEGOCIACIÓN}

Cuando uno escucha el término "proceso de negociación", en lo primero que piensa es en el acto mismo de negociar, esto es en el intercambio de propuestas y contrapropuestas; de ofertas y contraofertas; y/o en el cierre exitoso del mismo o en su fracaso. Sin embargo, el proceso de negociación tiene diversas etapas, diferentes a la dinámica misma del intercambio de ofertas y contraofertas. Así, en la doctrina se ha establecido categorizaciones diversas de las etapas de la negociación; y a efectos del presente artículo, hemos agrupado las mismas en cuatro etapas que grafican en términos generales las mismas, a decir: i) la planificación; ii) el desarrollo o negociación; iii) el cierre o acuerdo; y iv) el seguimiento o implementación. En esta oportunidad, queremos llamar la atención sobre la etapa de la panificación o preparación, la cual es de particular relevancia debido a su incidencia en las siguientes etapas del proceso de negociación; aquí identificadas. Incluso de ella puede depender el éxito o el fracaso del íntegro de la negociación.

La etapa referida a la preparación o pre negociación, constituye el punto de partida de la negociación. Conlleva la realización de actos preparatorios formales y por parte de los involucrados en el proceso. En esta etapa se realizan actividades como i) la investigación; ii) la identificación y definición de intereses (propios y de la otra parte); iii) la estrategia a ser utiliza en el proceso; iv) se analiza las capacidades reales y potenciales del equipo, entre otras, que puedan ser relevantes en el proceso.
En esta etapa se realiza la búsqueda de información que nos llevará a contar con los elementos suficientes para tener claridad sobre el conflicto que motiva nuestro ingreso al proceso de negociación así como de información que nos servirá para sustentar nuestra posición; de igual manera, nos permitirá conocer los intereses, circunstancias y posibilidades de la otra parte de la manera más completa posible. La búsqueda de información puede estar dirigida a identificar los antecedentes del conflicto y las circunstancias o contexto en el que el mismo se dio. Concluida la recopilación de la información, la misma deberá ser sistematizada para su posterior análisis y utilización en las siguientes etapas del proceso.

De igual manera, se deben definir con claridad cuáles son los objetivos y los intereses en la negociación. Así, el objetivo estará constituido por lo que deseamos lograr en la negociación. En el caso de negociaciones complejas es posible que se identifique más de un objetivo; si este fuera el caso, se deberá establecer una priorización. Luego se deberá proceder a identificar nuestros propios intereses y las posibilidades de éxito de los mismos, para así materializar los mismos en propuestas concretas.

Conocer los intereses de la otra parte es importante para evaluar de manera adecuada los alcances del proceso de negociación. El conocer estos intereses nos permitirá identificar tanto las posibilidades de concesión, así como los problemas o dificultades que podría enfrentar la otra parte, lo cual nos permitirá elaborar propuestas constructivas para facilitar el consenso en el proceso. Cabe indicar, sin embargo, que por definición, en las negociaciones las partes cuentan con información asimétrica respecto de cada una de ellas, razón por la cual el análisis de los intereses de la otra parte requiere de un trabajo de investigación muy exhaustivo. A tal efecto, se deberá recurrir a toda fuente posible, sea esta directa o indirecta.

No podemos dejar de destacar el hecho de que todo proceso de negociación es una vía de dos carriles. Si queremos obtener lo que buscamos, debemos tener claro que probablemente tengamos que realizar concesiones para atender los intereses de la otra parte. ¿Qué tanto estamos dispuestos a conceder?

En tal sentido, en función de los objetivos e intereses identificados, antes del inicio de la negociación, se 
deben establecer los parámetros o márgenes dentro los cuales se enmarcarán las propuestas, la contrapropuesta y el posible acuerdo; es decir, las líneas mínimas o líneas máximas de concesión (líneas rojas o líneas de resistencia), que determinarán nuestra permanencia o retiro del proceso de negociación.

En la planificación del proceso de negociación, además de lo anterior, también se desarrolla la estrategia. Procesada la información obtenida y definidos los intereses, corresponde entonces definir la estrategia a seguir en el proceso. ¿Qué estrategia seguir? ¿Negociaremos en base a los principios de la negociación integrativa o distributiva? ¿Queremos establecer vínculos a mediano o largo plazo? ¿Se trata de una negociación que se agota en una única vez? ¿Cuáles son nuestras otras alternativas? ¿Tenemos acaso una opción alternativa en caso la negociación fracase? Estas interrogantes son importantes de responder.

En la estrategia se definirán el plan general para lograr las metas propias en la negociación, así como la secuencia de acciones que conducirán a la obtención de esas metas. Se evaluará la pertinencia de desarrollar una estrategia de negociación competitiva (distributiva) o colaborativa (integrativa), o en todo caso, mixta. En la práctica, es poco probable que en una negociación se aplique un modelo puro; éstos suelen combinarse en función de los temas específicos que se negocian y en función del desarrollo de la negociación.

De igual manera, como parte de la estrategia se debe establecer la oportunidad en la que se presentarán las propuestas y se harán concesiones; cuál será la secuencia y la forma de presentación de los temas.

Es pertinente notar que en la definición de la estrategia no solamente se consideran aspectos sustantivos, sino formales, como el lugar de la negociación; la oportunidad y el tiempo de duración de la misma; los horarios y quienes participarán en la misma; y el idioma, entre otros aspectos.

Por otro lado, el contar con una alternativa viable frente al eventual fracaso de la negociación es sustancial pues ello podría determinar el margen de flexibilidad que tengamos en el proceso. Por ejemplo, si nos encontramos ante una situación en la que tengamos que negociar frente a un único proveedor, nuestro margen de negociación será mucho menor a si estamos en un mercado donde tengo otros proveedores a quiénes acudir en caso no llegue a un acuerdo con el primero. El negociador tiene que saber sobre la existencia o la no existencia de otra alternativa cierta a la cual acudir en caso fracase la negociación. Ello, antes de empezar el proceso de negociación.

El análisis de capacidad negociadora, por su parte, es un aspecto que está relacionado a la empatía del negociador y su capacidad de saber escuchar, comunicar y ser creativo en el proceso, para atender no sólo a nuestros intereses, sino también a los de la otra parte. Ello, a efectos de propiciar y facilitar el acuerdo. Hay que tener en consideración que muchas veces negociaremos en condiciones asimétricas. Sin embargo, ello no debería determinar el abandono de la negociación, sino la búsqueda de la oportunidad para la satisfacción de nuestros intereses y en ello, las habilidades propias del negociador, tienen mucho que aportar.

\section{LA PUESTA EN PRÁCTICA DE LA PLANIFICACIÓN: EL ACUERDO DE PROMOCIÓN COMERCIAL PERÚ - ESTADOS UNIDOS DE AMÉRICA}

Luego de haber expuesto y analizado las etapas en e proceso de negociación, pasaremos a graficar la aplicación de las mismas a un caso concreto. El Acuerdo de Promoción Comercial Perú-Estados Unidos de América (en adelante, el APC), constituye uno de los hitos en la experiencia negociadora del Perú. Significó un reto importante tanto por su potencial impacto en la economía del país como por la organización del proceso de negociación.

La negociación antes referida fue una negociación compleja en cuanto a fondo y forma. En cuanto a fondo, debido a la diversidad, amplitud y tecnicismo de los temas materia de negociación; y en cuanto a forma, debido a que la negociación fue planteada como una negociación bilateral entre EEUU y los Países Miembros de la Comunidad Andina (Colombia, Ecuador, Perú como países negociantes y Bolivia, como país observador), lo cual implicaba un nivel adicional de negociación y coordinación a todos los efectos, además de la coordinación interna.

La etapa preparatoria de esta negociación fue muy intensa. El Perú, en primer lugar, investigó y recopiló información sobre su potencial socio. Así, analizó los acuerdos comerciales que EEUU había negociado y suscrito a la fecha, así como su posición en los diversos foros multilaterales con relación a las materias incluidas en dichos acuerdos. Adicionalmente, se trabajó con los negociadores de países que ya tenían acuerdos comerciales suscritos con EEUU, tales como Chile, México y República Dominicana, a efectos de intercambiar información no solo sobre los temas sustantivos, sino sobre los aspectos formales del proceso. Ello permitió evaluar las posibles diferencias o semejanzas entre tales acuerdos, la legislación peruana y la legislación comunitaria andina (era previsible que las propuestas de EEUU estuvieran encaminadas en una línea similar a los Acuerdos previamente negociados); así como con la posición del Perú con relación a dichos temas en los diversos foros multilaterales.

Por otro lado, se trabajaron estudios de factibilidad para medir el potencial impacto de las políticas que se pudieran derivar de la implementación del acuerdo (e.g., políticas arancelarias, tributarias, comerciales). Estos estudios fueron realizados, tanto por centros de investigación independientes como por el Ministerio de Comercio Exterior y Turismo y Centrum (a requerimiento de Mincetur). 
En cuanto a la definición de objetivos e intereses, es importante precisar que el Perú era beneficiario del sistema de preferencias arancelarias otorgado unilateralmente por EEUU (ATPDEA), el cual tenía que ser renovado todos los años. Si bien estas preferencias eran beneficiosas para nuestro comercio, el hecho de que fueran unilaterales y transitorias generaba incertidumbre en los exportadores peruanos sobre la continuidad de sus actividades comerciales, limitando, además, posibles inversiones de largo plazo. Por otro lado, las mismas no cubrían todo el universo arancelario del Perú. Ante dicho escenario, uno de los objetivos principales del Perú, en el proceso, fue consolidar y ampliar las preferencias del ATPDEA, así como convertir las mismas en permanentes.

Siendo una negociación compleja, se identificaron como objetivos adicionales el incremento y la diversificación de nuestra oferta exportadora; el propiciar economías de escala; contribuir en mejorar la calidad de vida de las personas, a través de una mayor oferta y mejores precios de productos en el mercado; un incremento de la oferta laboral y un incremento de salarios, entre otros.

De igual manera, se identificaron los intereses nacionales en cada uno de los temas que se preveía serían negociados y se analizó su viabilidad en términos objetivos sobre la base de la información previamente recabada, así como su consistencia con el marco legal vigente, incluido el régimen comunitario andino. Los intereses de la otra parte se fueron identificando de los acuerdos previamente negociados; de las declaraciones realizadas por representantes del gobierno de EEUU; y de su posición sobre los temas relevantes en la Organización Mundial del Comercio, entre otras fuentes. Por otro lado, los intereses se clasificaron como temas ofensivos y defensivos, estableciéndose la oportunidad de su presentación o retiro, según fuera el caso; así como el margen de flexibilidad en cada uno de ellos y las líneas de resistencia. Se elaboró una matriz de objetivos, intereses y sensibilidades del Perú en la negociación.

En cuanto a la estrategia a aplicarse al proceso, considerando de que se trataba de una negociación que pretendía establecer una relación de largo plazo con un socio comercial, se consideró pertinente trabajar bajo un esquema de negociación colaborativo.

La capacidad negociadora fue fortalecida a través del establecimiento de una estructura y línea de dirección que estuvo liderada por i) el Jefe del Equipo Negociador, quien era el único vocero con nuestra contraparte y el encargado de dar las instrucciones para el trabajo en cada una de las mesas; y ii) el Comité Técnico Negociador, conformado por el Vice Ministro de Comercio Exterior y representantes de alto nivel de las autoridades competentes en las materias negociadas. Este comité tenía como principal función la implementación de las instrucciones brindadas por el Jefe de Equipo Negociador, así como fijar la posición técnica en cada tema y resolver los problemas que se podrían presentar durante la negociación, entre otras. Como parte de la estructura también se conformó el Comité Técnico Consultivo, compuesto por representantes del sector privado expertos en comercio exterior y líderes de opinión. Este comité apoyó con la sugerencia de estrategias para la solución de problemas, así como con las consultas formuladas por los negociadores. También formó parte de la estructura para fortalecer la capacidad negociadora nacional los Grupos de Negociación, quienes estuvieron encargados de la coordinación técnica interinstitucional (y con el sector privado) y de negociar los temas asignados bajo su responsabilidad con la contraparte. El equipo de negociación técnica fue capacitado en talleres de negociación provistos por reconocidos expertos en la materia a efectos de fortalecer sus capacidades en el proceso. Todo este proceso se dio entre agosto de 2003 y mayo de 2004 y sentó las bases para el proceso de negociación efectiva que se inició el 18 de mayo de 2004 y culminó el 07 de diciembre de 2005 con el cierre exitoso del Acuerdo.

De lo anterior, se desprende, para concluir, que la planificación de la negociación es esencial si buscamos llevar adelante un proceso de negociación exitoso, con independencia de la dimensión del proceso de negociación, pues ello nos permitirá contar con la información necesaria para una correcta medición de los alcances de la negociación y el establecimiento de una estrategia que nos permita obtener un acuerdo beneficioso para ambas partes.

\section{REFERENCIAS}

Flint, P. (2001). Negociaciones eficaces. Lima: Empresa Editora el Comercio. 